\title{
Reliability of photovoltaic modules based on climatic measurement data
}

\author{
R. Laronde ${ }^{\star}$, A. Charki ${ }^{\star \star}$, and D. Bigaud ${ }^{\star \star \star}$ \\ University of Angers, LASQUO Laboratory, France
}

Received: 15 January 2010 / Accepted: 5 March 2010

\begin{abstract}
In the building domain, components or equipment are often subjected to severe environmental conditions. In order to predict the reliability and the life-time of such equipment, accelerated life testing can be carried out. Severe conditions are applied to accelerate the ageing of the components and the reliability at nominal conditions is then deduced considering that these nominal conditions are not constant but stochastic. In this paper, the accelerated life testing of photovoltaic modules is carried out at severe module temperature levels. The module power losses are monitored and the limit state is determined when a threshold power is reached. The stochastic data and the reliability are simulated during a period of twenty years. Finally, the life time of the component is evaluated.
\end{abstract}

Keywords: Life-time; accelerated life testing; malfunctioning; reliability law; stochastic; photovoltaic module

\section{Introduction}

Photovoltaic modules are used all around the world in order to produce electricity from solar energy. Manufacturing photovoltaic modules is costly and the components are polluting. To be qualified as renewable energy, they must be reliable and have a long life time.

Components lifetime is usually modeled in a deterministic way by considering a constant stress or a predefined mission profile (Fig. 1). As for the estimation of the behavior during time or after a given period of time, one commonly uses classical laws such as exponential, Weibull or log normal distribution combined with standard acceleration laws such as Arrhenius, Peck or inverse-power. This article proposes a study of the influence of random environmental conditions on photovoltaic modules performance (energy power). The performance depends largely on weather conditions such as temperature, humidity and UV radiations which are stochastic. It is also known that these parameters depend on solar time, season and location.

In the literature, the reliability evaluation of photovoltaic modules was discussed by Tsuda et al. [1] and Vázquez and Rey-Stolle [2] who developed accelerated testing programs for crystalline silicon photovoltaic modules using aim tests of IEC 61215 standard (i.e. damp heat testing, thermal cycle testing, thermal shock, cyclic illumination, UV exposure) and other testing like "humidity test" [1].

\footnotetext{
^ Correspondence: remi.laronde@univ-angers.fr

${ }^{\star \star}$ Correspondence: abderafi.charki@univ-angers.fr

${ }^{\star \star \star}$ Correspondence: david.bigaud@univ-angers.fr
}

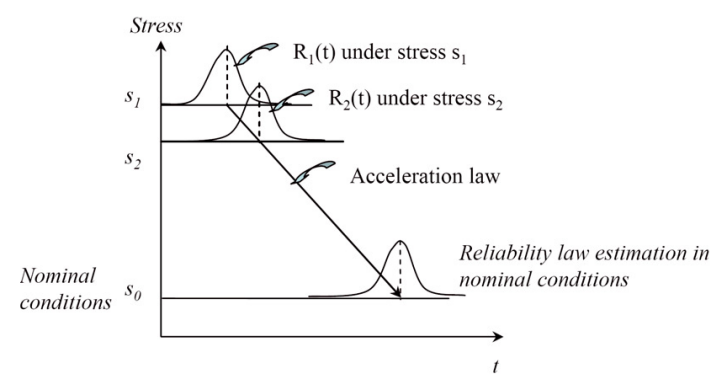

Fig. 1. Reliability assessment using accelerated life testing.

Wohlgemuth et al. [3] has mainly studied damp heat testing and thermal cycle testing but with time longer or other levels than the standard. However, all the studies have produced neither the relation with the nominal conditions from accelerated life testing nor the stochastic side of nominal conditions.

The lifetime study using stochastic parameters has also been discussed by Voiculescu et al. [4] who present statistical and time depending approaches of the reliability in random environment.

In this paper, we present a model developed in order to simulate the influence of parameters on the reliability of photovoltaic modules. The effect of temperature variations is essentially focused. In the proposed approach, Arrhenius acceleration law and Weibull lifetime distribution are used.

\section{Lifetime estimation}

\subsection{Lifetime distribution}

Weibull distribution is the most popular lifetime distribution. It is used in electronics as well as in mechanics. 
It is accurate for the three stages of the product life: infant mortality, steady state and wear out period [5]. In this study, we consider that the lifetime distribution of photovoltaic modules [6] can be expressed as:

$$
R(t)=e^{-\left(\frac{t}{\eta}\right)^{\beta}}
$$

with $\eta$ the scale parameter and $\beta$ the shape parameter of Weibull law.

\subsection{Reliability under constant stress conditions}

Arrhenius model is usually used for components when the damaging mechanism is due to the influence of temperature [7]. Thus, Arrhenius model defines the component lifetime $\tau$ as [5]:

$$
\tau=e^{\gamma_{0}+\frac{\gamma_{1}}{T}}
$$

where $\gamma_{0}$ and $\gamma_{1}$ are Arrhenius model parameters and $T$ is the temperature $(\mathrm{K})$. In Weibull distribution, the scale parameter is the product lifetime, then $\eta=\tau$.

In constant nominal conditions, the temperature $T$ is a constant parameter. After the determination of $\gamma_{0}$ and $\gamma_{1}$, the reliability function becomes:

$$
R(t)=e^{-\left(\frac{t}{e^{\gamma_{0}+\frac{\gamma_{1}}{T}}}\right)^{\beta}}
$$

This reliability function is related to the power losses of the photovoltaic module. The lifetime which can be calculated by inversion of equation (3) corresponds to the time necessary to reach a target value of power $P_{\text {target }}(T)=$ $50 \% P_{t=0}(T)$.

\subsection{Reliability in stochastic conditions}

As mentioned in paragraph 1 , variables in accelerated life testing models can actually be stochastic in the real-life, which is true when the component is exposed to outdoor environment. Thus, to determine the reliability of a component under nominal conditions, three steps must be treated:

- determining the value of the scale factor and shape factor of the lifetime distribution (Weibull law) for each severe level;

- calculating parameters $\gamma_{0}$ and $\gamma_{1}$ of the Arrhenius model;

- transforming reliability functions obtained at severe temperatures $R\left(t, T_{\text {test }}\right)$ into the reliability function at nominal conditions $R\left(t, T_{i}\right)$.

The first step consists in following reliability $R(t, T)$ as a function of time. It allows determining the shape parameter $\beta$ of Weibull law. As the scale factor $\eta$ is assumed to depend on the temperature (Eq. (2)), several reliability curves corresponding to several temperature levels are necessary. It permits to completing the second step and obtaining the Arrhenius model parameters.

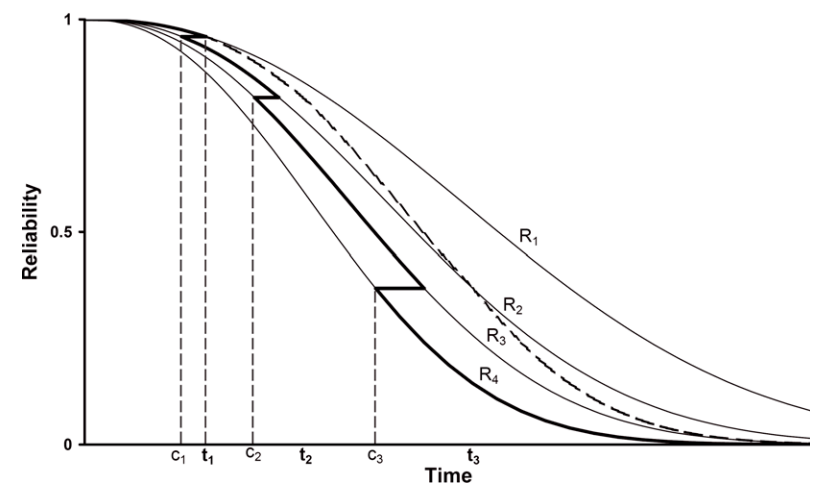

Fig. 2. Reliability of component with stochastic stress.

The third step aims at transforming the reliability functions obtained at different temperature levels $T_{i}$ into the reliability under nominal conditions $T_{i}$ (cf. Fig. 2).

If reliability is built incrementally for successive times $t_{i-1}<t \leq t_{i}$, the reliability function $R\left(t, T_{i}\right)$ at nominal conditions becomes [4]:

$$
R\left(t, T_{i}\right)=e^{-\left(\frac{\left(t-t_{i-1}\right)+c_{i-1}}{\eta\left(T_{i}\right)}\right)^{\beta}}
$$

with:

$$
c_{i-1}=\eta\left(T_{i}\right) \sum_{k=1}^{i-1} \frac{t_{k}-t_{k-1}}{\eta\left(T_{k}\right)}
$$

and:

$$
\eta\left(T_{i}\right)=e^{\gamma_{0}+\frac{\gamma_{1}}{T_{i}}}
$$

\section{Simulation data}

\subsection{Module temperature data}

\subsubsection{Module temperature}

The photovoltaic module temperature $T_{\text {module }}(\mathrm{K})$ depends on the ambient temperature $T_{\mathrm{amb}}(\mathrm{K})$ and the solar irradiance $G\left(\mathrm{~W} / \mathrm{m}^{2}\right)$ [8]. It can be expressed as:

$$
T_{\text {module }}=T_{\mathrm{amb}}+\frac{G}{800}\left(T_{\mathrm{NOCT}}-20\right)
$$

with $T_{\mathrm{NOCT}}$, the nominal operating cell temperature $\left({ }^{\circ} \mathrm{C}\right)$ obtained with an irradiance of $800 \mathrm{~W} / \mathrm{m}^{2}$, an ambient temperature of $20{ }^{\circ} \mathrm{C}$, a wind speed of $1 \mathrm{~m} / \mathrm{s}$ and a photovoltaic modules inclination of $45^{\circ}$ [9].

Irradiance $G$ and the ambient temperature $T_{\text {amb }}$ are stochastic. Their dependency on time is explained below.

\subsubsection{Irradiance}

IEC 61725 standard [10] is used to express the irradiance evolution over one day. This standard gives the analytical profile for daily solar illumination (cf. Fig. 3) from sunrise to sunset. 


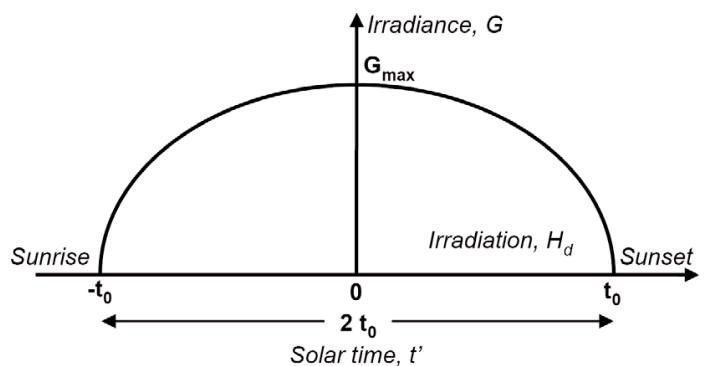

Fig. 3. Analytical profile for daily solar illumination.

In Figure $3, G_{\max }\left(\mathrm{W} / \mathrm{m}^{2}\right)$ is the maximum solar irradiance at solar midday (i.e. $\left.t^{\prime}=0\right)$ and $H_{d}\left(\mathrm{Wh} / \mathrm{m}^{2}\right)$ is the daily solar irradiation for given photovoltaic modules inclination. The used mean of $G_{\max }$ and $H_{d}$ are thus of meteorological institute in studied location. These values are constant for one day $(24 \mathrm{~h})$.

For $-t_{0} \leq t^{\prime} \leq t_{0}$, the expression of $G$ is expressed as:

$$
G=\left[\begin{array}{c}
G_{\max } \cos \left(\frac{t^{\prime}}{t_{0}} \frac{\pi}{2}\right) \\
\times\left[1+s\left(1-\cos \left(\frac{t^{\prime}}{t_{0}} \frac{\pi}{2}\right)\right)\right]+\xi_{G}
\end{array}\right]
$$

where $\xi_{G}$ is a random variable and $s$ is the form factor:

$$
s=\frac{\frac{H_{d}}{G_{\max } 2 t_{0}} \frac{\pi}{2}-1}{1-\frac{\pi}{4}} .
$$

If the meteorological institute does not give the mean daily irradiation $H_{d}$, the form factor becomes $s=0$.

\subsubsection{Ambient temperature}

In this part, the ambient temperature $\left(T_{\mathrm{amb}}\right)$ will be formalized in function of the daily temperature $\left(T_{\text {day }}\right)$ using a sinusoidal form.

The ambient temperature value in the atmosphere depends on the location, the season and the time of the day. For the first two, monthly ambient temperatures recording can be given by national meteorological institutions. For the third part, the ambient temperature evolution over one day must be determined.

The ambient temperature was measured from November 1st, 2008 to December 21st, 2008 every 20 min with a thermometer. Results are given in Figure 4.

We can see in Figure 4 that the temperature has a great variance. The values of November 2008 permit determining the mean daily temperature $T_{\text {day }}$. It follows a normal law for which the mean and the standard deviation are respectively: $\mu_{T_{\text {day }}}=7.52{ }^{\circ} \mathrm{C}$ and $\sigma_{T_{\text {day }}}=3.24{ }^{\circ} \mathrm{C}$. To generalize this data, the used mean of $T_{\text {day }}$ will be the one provide by the meteorological institute in the studied location. This value is constant for one day $(24 \mathrm{~h})$.

In order to determine the ambient temperature function, the daily temperature is centered on zero as shown in Figure 5.

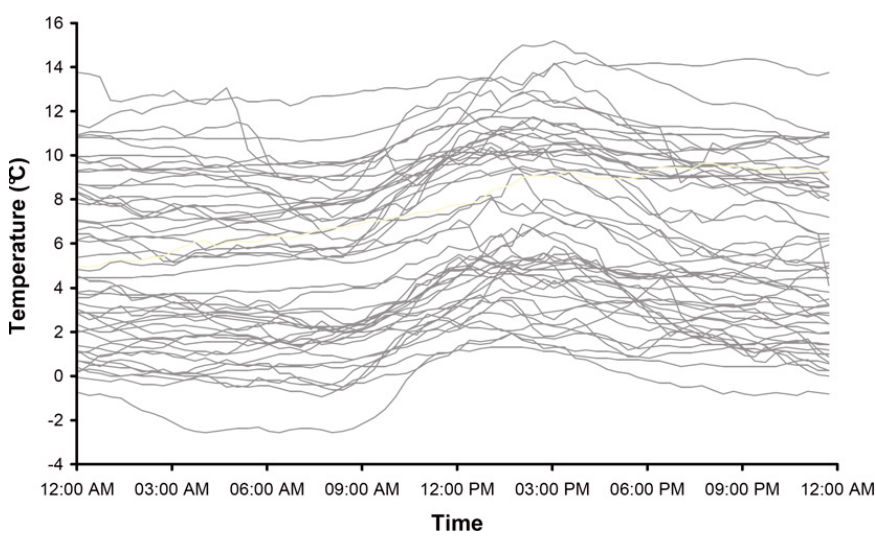

Fig. 4. Measured temperature data.

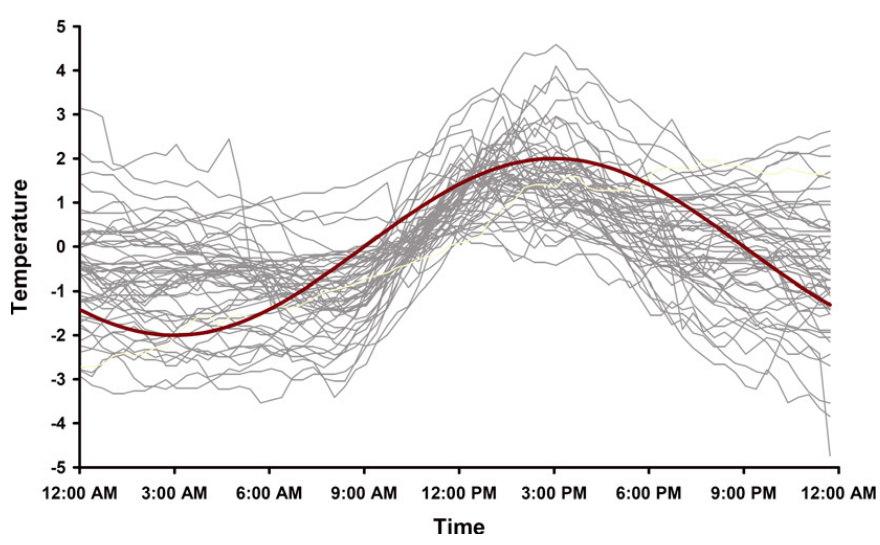

Fig. 5. Temperature data with $T_{\text {day }}$ normalized on zero.

From these data, the interpolated function of the instantaneous ambient temperature $T_{\mathrm{amb}}$ in atmospheric conditions is deduced as:

$$
T_{\mathrm{amb}}=T_{\text {day }}+\frac{\Delta T}{2} \cos \left(\frac{t^{\prime}-1}{t_{0}} \frac{\pi}{2}\right)+\xi_{T}
$$

where $\xi_{T}$ is a random variable and $\Delta T$ is the interval between maximum and minimum temperatures during a day (the mean of these parameters on the measured values gives $\left.\Delta T=4{ }^{\circ} \mathrm{C}\right)$.

Equation (10) is plotted in Figure 5 (thick curve). This equation follows the same trend that of the real values.

Finally, for one day, the parameter $\xi_{T}$ is a zero mean Gaussian random variable with standard deviation of $1.00{ }^{\circ} \mathrm{C}$.

\subsection{Simulation}

Simulink ${ }^{\circledR}$ is used for simulating module temperature and for estimating the time-variant performance. The simulation in Simulink ${ }^{\circledR}$ is separated into two blocks (cf. Fig. 6). The first block represents meteorological data using equations from Section 3.1. The second block represents timevariant performance using equations from Section 2.3. 


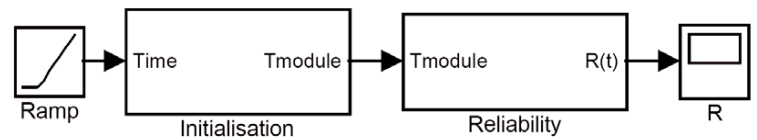

Fig. 6. Simulation with SIMULINK ${ }^{\circledR}$.

Table 1. Accelerated life testing data.

\begin{tabular}{ccc}
\hline$i$ & Time at $353 \mathrm{~K}(\mathrm{~h})$ & Time at $373 \mathrm{~K}(\mathrm{~h})$ \\
\hline 1 & 14415 & 10773 \\
2 & 20637 & 15542 \\
3 & 25175 & 18894 \\
4 & 29222 & 21850 \\
5 & 32877 & 24670 \\
6 & 36637 & 27472 \\
7 & 40454 & 30354 \\
8 & 44889 & 33698 \\
9 & 50339 & 37661 \\
10 & 58572 & 43884 \\
\hline
\end{tabular}

\subsubsection{Input data}

$\beta, t_{0}$ and $\Delta T$ are constant data and they are determined from testing and experience feedback. $\gamma_{0}$ and $\gamma_{1}$, determined by accelerated life testing, are constant data for one simulation and they follow a probability distribution for each simulation ( $\gamma_{0}$ is a normal random variable and $\gamma_{1}$ a lognormal random variable). Then, $T_{\text {day }}, G_{\max }$ and $H_{d}$ are constant data during a day and they follow a probability distribution for every day ( $T_{\text {day }}$ and $G_{\max }$ are a normal random variables and $H_{d}$ is constant) with means changing every month. Finally, $\xi_{T}$ and $\xi_{G}$ are random variables.

\subsubsection{Output data}

Output data of simulation is the time-dependent reliability $R(t)$. The evolution of module temperature $T_{\text {module }}$ which is an important intermediate data can also be monitored.

\section{Application: photovoltaic module}

Table 1 presents the simulated lifetime for temperature maintained at two different levels: $80{ }^{\circ} \mathrm{C}(353 \mathrm{~K})$ and $100{ }^{\circ} \mathrm{C}(373 \mathrm{~K})$. The failure times follows a Weibull distribution with $\beta=2.6, \eta_{80}{ }^{\circ} \mathrm{C}=40000 \mathrm{~h}$, and $\eta_{100}{ }^{\circ} \mathrm{C}=$ $30000 \mathrm{~h}$. This permits obtaining the two parameters of the Arrhenius model: $\gamma_{0}=5.22$ and $\gamma_{1}=1898.0$.

In order to provide a confidence level of $90 \%$, Bootstrap method is used [11]. It consists in creating artificial lists by randomly drawing elements from some list of data. Some elements will be used more than once. 500 simulations are carried out thus $500 \gamma_{0}$ and $500 \gamma_{1}$ permit determining confidence intervals.

$$
\begin{gathered}
1.93 \leq \gamma_{0} \leq 8.51 \\
1006.9 \leq \gamma_{1} \leq 3577.4
\end{gathered}
$$

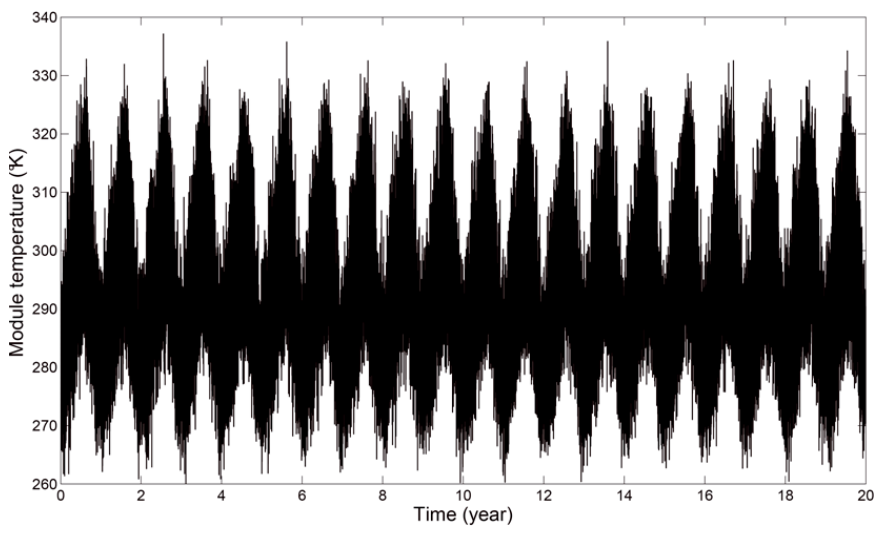

Fig. 7. Photovoltaic module temperature.

Table 2. Meteorological data.

\begin{tabular}{cccc}
\hline Month & $\begin{array}{c}T_{\text {day }} \\
\left({ }^{\circ} \mathrm{C}\right)\end{array}$ & $\begin{array}{c}G_{\max } \\
\left(\mathrm{W} / \mathrm{m}^{2}\right)\end{array}$ & $\begin{array}{c}H_{d} \\
\left(\mathrm{~W} \mathrm{~h} / \mathrm{m}^{2}\right)\end{array}$ \\
\hline January & 3.9 & 316 & 1910 \\
February & 4.7 & 406 & 2690 \\
March & 7.7 & 553 & 4120 \\
April & 9.8 & 599 & 4880 \\
May & 14.2 & 539 & 4810 \\
June & 17.9 & 613 & 5540 \\
July & 19.6 & 708 & 6060 \\
August & 19.6 & 680 & 5560 \\
September & 15.7 & 644 & 4830 \\
October & 13.0 & 473 & 3240 \\
November & 6.9 & 366 & 2290 \\
December & 4.2 & 273 & 1580 \\
\hline
\end{tabular}

The deviation is very high because only 10 samples are taken into account.

Afterward, atmospheric conditions are simulated to have the nominal conditions. The module temperature depends on both the ambient temperature and the irradiance. Thus these two stochastic parameters have been simulated using meteorological data and the simulation developed with SIMULINK ${ }^{\circledR}$.

Meteorological data from Clermont-Ferrand (France) (available on the website PVGIS - Meteorological data for Europe and Africa) have been used (cf. Tab. 2). Photovoltaic modules have an inclination of $35^{\circ}$ and they face the south. Moreover, the photovoltaic module temperature is $T_{\mathrm{NOCT}}=47^{\circ} \mathrm{C}$.

For the simulation, the normal law is used for each variable. $\Delta T$ and $H_{d}$ are considered constant with $\Delta T=$ $4 \mathrm{~K}$ and $H_{d}$ values are given in Table 2. The standard deviations values of $G$ and $G_{\max }$ are chosen by authors. These values can be estimated using measurement data.

Figure 7 shows the photovoltaic module temperature simulated during 20 years.

Figures 8 and 9 present the reliability function. 50 simulations per figure have been performed.

In Figure 8, reliability is calculated using $\gamma_{0}$ and $\gamma_{1}$ standard deviations equal at zero. Evolutions of timedependent reliability are nearly the same. The mean time to failure (MTTF) is $124856 \mathrm{~h} \pm 318 \mathrm{~h}$ (14253 years \pm 


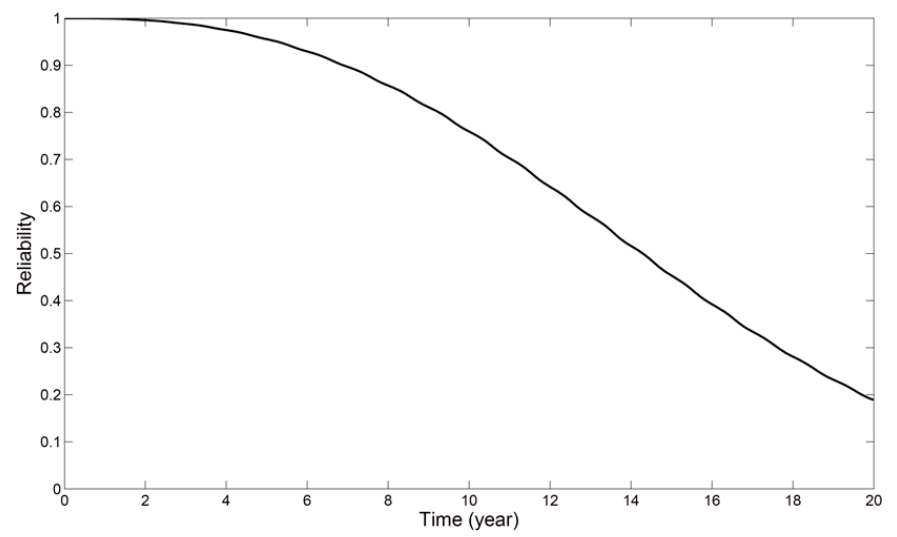

Fig. 8. Photovoltaic module reliability without standard deviation.

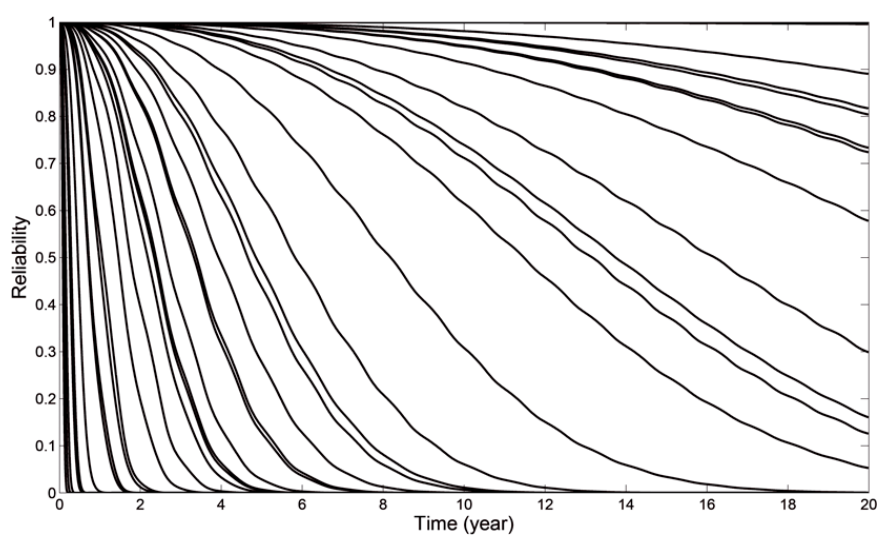

Fig. 9. Photovoltaic module reliability.

Table 3. Random variables.

\begin{tabular}{ccccc}
\hline Var. & Units & Law & Mean & Std. dev. \\
\hline$\beta$ & - & Constant & 2.6 & - \\
$\gamma_{0}$ & - & Normal & 5.22 & 2.00 \\
$\gamma_{1}$ & $\mathrm{~K}$ & Lognormal & 1898.0 & 731.4 \\
$t_{0}$ & $\mathrm{H}$ & Constant & 6.0 & - \\
$T_{\text {day }}$ & $\mathrm{K}$ & Normal & cf. Table 2 & 3.5 \\
$\Delta T$ & $\mathrm{~K}$ & Constant & 4 & - \\
$\xi_{T}$ & $\mathrm{~K}$ & Normal & 0.0 & 1.0 \\
$G_{\max }$ & $\mathrm{W} / \mathrm{m}^{2}$ & Normal & cf. Table 2 & 80 \\
$H_{d}$ & $\mathrm{~W} \mathrm{~h} / \mathrm{m}^{2}$ & Constant & cf. Table 2 & - \\
$\xi_{G}$ & $\mathrm{~W} / \mathrm{m}^{2}$ & Normal & 0.0 & 50 \\
\hline
\end{tabular}

0.036 years) for a confidence level of $90 \%$. That confidence interval and reliability evolutions signify that standard deviations of random variables do not greatly impact the time-dependent reliability and the mean time to failure.

However, when $\gamma_{0}$ and $\gamma_{1}$ standard deviations are taken into account, evolutions of time-dependent reliability are very different (cf. Fig. 9). That is due to the uncertainty-spreading of an accelerated life testing and a large deviation of parameter due to Bootstrap method.

\section{Conclusion and perspectives}

This article presents a methodology for the evaluation of the reliability of a photovoltaic module which is subjected to a stochastic condition: the module temperature depending on ambient temperature and irradiance. According to testing data listed in Table 1, the accelerated life testing is very long (7 years) and we obtained finally a lifetime of 14 years. However, some manufacturers announce a photovoltaic modules lifetime of 25-30 years and they can not carry out accelerated testing of 7 years. We must reduce the testing time. Several methods exist to do this. It would be interesting to decrease the testing-time at higher temperature but it is impossible because photovoltaic modules have a technological limit at $120^{\circ} \mathrm{C}(393 \mathrm{~K})$. To decrease the testing-time, other parameters can be taken into account like humidity and UV radiation; other acceleration laws would be used in these cases. Moreover, the great variability of reliability curves of Figure 9 can be reduced by conducting another test with a temperature condition close to the mean nominal temperature.

Acknowledgements. This research was supported by the "Région Pays de la Loire" (a French region). This support is gratefully acknowledged.

\section{References}

1. I. Tsuda, S. Igari, K. Nakahara, K. Takahisa, K. Morita, H. Kato, Long term reliability evaluation of PV module, in 3rd World Conference on Photovoltaic Energy Conversion (2003), pp. 1960-1963

2. M. Vázquez, I. Rey-Stolle, Prog. Photovolt. Res. Appl. 16, 419 (2008)

3. J.H. Wohlgemuth, D.W. Cunningham, M. Nguyen, J. Miller, Long term reliability of PV modules, in 20th European Photovoltaic Solar Energy Conference (2005), pp. $1942-1946$

4. S. Voiculescu, F. Guerin, M. Barreau, A. Charki, A. Todoskoff, Reliability estimation in random environment: Different approaches, RAMS 2007 (2007), pp. 202-207

5. W.B. Nelson, Accelerated Testing: Statistical Models, Test Plans and Data Analyses (Wiley-Interscience, 1990)

6. F. Guerin, P. Lantieri, B. Dumon, Applying accelerated life models to halt testing, in 9th ISSAT International Conference on Reliability and Quality Design (2003)

7. S. Voiculescu, F. Guerin, M. Barreau, A. Charki, Int. J. Product Development 7, 246 (2009)

8. R.P. Kenny, E.D. Dunlop, H.A. Ossenbrink, H. Müllejans, Prog. Photovolt. Res. Appl. 14, 155 (2006)

9. IEC 61215, Crystalline silicon terrestrial photovoltaic (PV) modules - Design qualification and type approval (2005)

10. IEC 61725, Analytical expression for daily solar profiles (1997)

11. P. Compère, Revue de Statistique Appliquée 45, 21 (1997) 